\title{
Central accountability and local decision making: towards a new NHS
}

\author{
PATRICIA DAY, RUDOLF KLEIN
}

It was unfortunate perhaps for Mr Victor Paige that the first time that many people in Britain read about his activities in their newspapers was when they learnt that the chairman of the new National Health Service Management Board had sanctioned plans for 2250 extra maternity cases in the Trent region in 1985-6. It was a story that, in the form that it appeared, implied a somewhat excessive degree of control by the Department of Health and Social Security over the lives of the population. If the story suggested some misleading conclusions it also reflected the emergence of a more directive and interventionist style of management in the NHS. It is not a style that Mr Paige and his board have created. On the contrary, the appointment of $\mathrm{Mr}$ Paige and his board simply represents the last, logical step in a process that is gradually transforming the style of management in the NHS and the relationship between the DHSS and the health authorities: a process crystallised but not caused by the Griffiths report. ${ }^{2}$ And it is a transformation that has profound long term implications for the way in which health care policies are defined and implemented, and perhaps also for the structure of the NHS.

$\mathrm{Mr}$ Paige's startlingly precise prediction of the number of maternity cases in the Trent region provides a good starting point to explore these implications. The source for the news about $\mathrm{Mr}$ Paige's decision was a DHSS press handout setting out details of the plans for next year agreed between the DHSS and the regional health authorities : an annual process linked to the system performance reviews that started in $1983 .{ }^{+}$Under this system DHSS ministers meet the regional chairmen annually to discuss and agree action plans; in turn, the regional chairmen then are expected to carry out a similar exercise with their district health authorities. The targets agreed between the DHSS and the regions do not therefore necessarily represent a departmental diktat, but are the product of a process of negotiation. In effect, the DHSS responds to, modifies, and sometimes imposes its own priorities on the plans put forward by the regions.

The plans are the product of negotiation and bargaining. But it is clear that the two partners do not bargain on equal terms. The regions may propose but it is the DHSS that disposes. This emerges clearly from the manpower targets announced by $\mathrm{Mr}$ Paige: in other words, the inputs into the NHS. This concern with inputs as distinct from outputs - that is, the resources going into the services as distinct from the number of patients treated, etc, coming out of it-is longstanding. For example, control over consultant posts has been one of the Department's most effective instruments for achieving a better distribution of resources, both geographically and between specialties, almost since the start of the NHS.

The latest round of manpower targets shows that the Department's long term concern with inputs is undiminished by its more recent interest in outputs. And, in this instance, it is the DHSS's decision that is final. Thus, five regions will have to settle for fewer staff than they asked for. The DHSS's insistence on determining the precise number of people to be employed in each region, and

Centre for the Analysis of Social Policy, School of Humanities and Social Sciences, University of Bath, Claverton Down, Bath BA2 7AY

PATRICIA DAY, BSC, research officer

RUDOLF KLEIN, MA, professor of social policy

Correspondence to: Ms Day. therefore indirectly in each district, is all the more remarkable given that the Department is in firm control of budgetary allocation. So, in effect, the Department is laying down how the money should be spent, as well as the total. There would seem to be little scope for local decisions about the appropriate mix of manpower, possibly substituting a larger number of cheaper workers for more expensive professionals.

\section{Increased control over output}

What is really new about the interventionist style of management, however, is that the DHSS is increasingly asserting control over the outputs of the NHS. It is asking regions to set output targets against which their performance may then be measured. And although the extent to which ministers and servants modify the targets set by the regions themselves is not known, it seems reasonable to assume that the DHSS would not have set up the whole elaborate system of performance reviews merely to rubber stamp the plans produced by the health authorities. Quite clearly, the system is designed to strengthen the DHSS's ability to promote its own ideas and priorities about what kind of services should be provided at regional and district level, and to tie down health authorities to specific aims for their own performance.

Mr Paige's target of 2250 extra maternity patients in the Trent region in 1985-6 is one example of how specific are some of the output objectives now being negotiated with regional authorities. The same press release gave details of other, similarly detailed plans. Thus the West Midlands region is to handle an extra 315 patients with rheumatology, while the North Western region is to offer an additional 200 open heart operations and an extra 150 patients renal dialysis. Moreover, the picture of growing DHSS participation with the details of service delivery at the periphery is confirmed by the minutes of the annual performance review meetings held between ministers and regional chairmen since 1982 . These minutes have been deposited in the House of Commons library and thus are in the public domain although not formally published. The DHSS has made them available to us—for which we are grateful-and in what follows we quote from records of the meetings held in 1984: records that, of course, do not give a picture of the negotiating process but only of the formal conclusions reached.

Thus, the North Western Regional Health Authority was set the task of producing a "timed programme for reducing by 1993 at least $50 \%$ of the current variations in access rates to acute services." Mersey Regional Health Authority was asked to "specify a programme for achieving an annual take up rate of not less than 40 new renal patients per million"-an objective that provides a common theme for most of the regional reviews. North East Thames Regional Health Authority was told to report progress on: " $(a)$ the planning of the 20 bed psychiatric intensive care unit at Friern and the 12 bed unit at Hackney and $(b)$ the designation of interim services at Friern and Hackney." South Western Regional Health Authority was asked to "report on proposals for further expansion in cardiac surgery to 600 cases per annum in Bristol" and "to submit a timed programme for transferring those long stay children under 16 years of age, currently in mental handicap hospitals . . . to more appropriate accommodation." Mr Paige's press release-although perhaps prompted by a desire to demonstrate publicly that improved productivity can yield better services even at a time of budgetary constraints-simply illustrates the DHSS's growing concern with the fine print of service delivery. 
In part, the DHSS's new interest in central control seems to be a response to parliamentary criticism. At the start of the 'eighties a series of reports from the Social Services Committee and the Public Accounts Committee sharply criticised the Secretary of State for his lack of grip over the NHS's administration and finances. ${ }^{56}$ Ministers and their civil servants, cross examined by members of parliament, found themselves in the embarrassing position of having to admit to ignorance about what was happening to the delivery of services in the NHS as a result of reductions in the planned level of expenditure growth and so called "efficiency savings." Challenged to explain the effects of these policy changes on the availability of care to patients, DHSS witnesses floundered. The development of a system for setting specific output objectives, and monitoring progress towards them, can thus be seen as a way of relating the inputs of resources into the NHS (money) and the production of outputs (services).

\section{Management vocabulary becoming universal}

The transformation of the administrative style in the NHS also reflects, however, a more general change that has affected government departments and public services. Economic scarcity has made the vocabulary of management the universal language of Whitehall. The manifesto of this new philosophy of government can be found in the 1982 report on efficiency and effectiveness in the Civil Service. This emphasised that it should be the responsibility of all departments to promote "an organisation and system in which managers at all levels have: $(a)$ a clear view of their objectives and means to assess and, wherever possible, measure outputs or performance in relation to these objectives; $(b)$ well defined responsibility for making the best use of their resources including a critical scrutiny of output and value for money."

This kind of system is essential, a subsequent white paper argued, not only to increase efficiency but to create an effective system of accountability: "Managers need to know how much they may spend; why they should spend it; and how their expenditure and results through the year compare with the plan. While the centre of the department receives regular information about the use of resources and the effectiveness of activities individual managers can then be held accountable for their performance."

The implications of this new style of government for the structure of management in the NHS are profound and range far beyond the immediate impact of the Griffiths report. Firstly, they promise, in the long term at any rate, to make a reality of what has, until now, been the semifiction of ministerial accountability to parliament. For the theory of parliamentary accountability - that is, the doctrine that ministers are answerable to the House of Commons for everything that happens in the NHS because the service is financed out of public money-has been undermined in practice by the ignorance of ministers about what is happening at the coal face. Secondly, the changes will also make it possible to debate in detail what the NHS should be trying to do. Until now policy debates in parliament have been largely about the broad priorities that should be pursued. But once explicit service objectives start to be set it becomes possible to debate the detailed aims of the NHS. In other words, changes in the system of management in the NHS may eventually lead to changes in the system of political control by creating an opportunity for a national debate about precisely what the service should be doing.

The development of a system for defining objectives at the national level, and for assessing performance at the operational level, promises to bring about the most important transformation in the history of the NHS. Since 1948 the services delivered have reflected as much the idiosyncratic and divergent priorities of local clinicians and health authorities as explicit central government policies. Now there is the prospect of an NHS that actually lives up to its name-that is, a national service whose local patterns of provision and activity reflect national policies, not only about inputs but also about outputs. But before celebrating the final apotheosis of the 1948 vision, ironically achieved through the management philosophy of a Conservative government, it is important also to take into account some of the problems that this is likely to bring about if the logic of the present, still tentative approach to setting output objectives is pursued with consistency and rigour.

\section{Equating increased activity and effectiveness}

Firstly, there is the problem of how the objectives of the NHS should be defined. What should be the language of objectives? In the 'seventies the language of objectives was that of service inputs. The priority documents published by the Labour government set the objectives of the NHS in terms of the balance of resources that should be devoted to various client groups, and set specific manpower and other targets for service inputs. ${ }^{910}$ Now, as $\mathrm{Mr}$ Paige's press release and the evidence of the performance review show, the language of objectives is changing. It is becoming that of service outputs. The emphasis is on increasing not what is being put into the NHS (the 'seventies mode, when optimism about economic growth had not yet died) but what is coming out of it: so many extra births in hospital, so many extra open heart operations, so many extra patients with rheumatology. But if the new style is an improvement on the 'seventies way of thinking about objectives it carries its own dangers. It is that outputs might be seen as an end in themselves: that increased activity will be equated with improved effectiveness. The point may be illustrated simply by taking the example with which this paper opened: $\mathrm{Mr}$ Paige's announcement that there will be 2250 extra maternity patients in the Trent region in 1985-6. This seems to confuse means and ends. The objective of this policy decision is, presumably, to lower risk to mothers and children. It could, therefore, be expressed in terms of the desired outcome-for example, a lower mortality rate.

There are obvious, much discussed problems about defining and measuring outcomes in health care. ${ }^{11}$ But to the extent that it is possible to move in this direction there would be less danger of the kind of perverse side effects that could result from setting output targets. Such targets are all about increasing productivity: a response, in part at least by the DHSS and ministers, to the criticism that the resources of the NHS are not adequate to sustain an acceptable degree of activity. But greater outputs and increased productivity may be achieved by a variety of means-for example, by cutting corners, by reducing quality, or by pursuing inappropriate activity. Equally, improved productivity may also accentuate budgetary pressure if the result is to increase the number of procedures carried out.

Secondly, there is the problem that the more specitic the objectives of the NHS become the greater will be the pressures to concentrate resources on those services that have a high degree of political, emotional, and media visibility. Output objectives are most easy to define and set in those service areas where specific procedures are being carried out. And, compounding this methodological bias, output objectives are most likely to attract public attention if they include procedures designed to deal with life threatening conditions, such as open heart operations. Thus, a system of output objectives could tilt the balance of NHS activities towards these forms of activity that lend themselves most easily to professional and political dramatisation, as distinct from those services concerned with quality of care or enhancing the quality of life. Such a bias is not inevitable. In the case of the performance reviews, quoted above, some of the objectives are being set in terms of the kind of services deemed desirable for the chronically ill. Equally, it is possible to set output targets for the number of hip operations or cataracts dealt with. But if this kind of balance is to be achieved it will mean explicitly taking into account the political and professional pressures pulling in the opposite direction.

Thirdly, there is the problem of whether a system of nationally agreed objectives, with strict and detailed accountability for performances to central government and parliament, could be compatible with the present structure and status of health authorities. The role of health authorities and their members has always been ambiguous. ${ }^{12}$ Nye Bevan regarded them as his agents or creatures, but as recently as 1981 , when the new health authorities were being set up, the Secretary of State told them: "You have a wider 


\section{Medical certificates under the Social Security Acts}

The General Medical Services Committee's solicitors have given the following advice on the issue of medical certificates under the Social Security Acts.

"Ever since the start of the National Health Service in 1948 general practitioners have been under an obligation to provide certain types of medical certificates for their patients. Although the wording of the terms of service has varied slightly the legal meaning has remained unchanged.

"The present paragraph 31 of the terms of service requires the general practitioner to issue for his patients, free of charge, 'the certificates prescribed in schedule 3 to these regulations being medical certificates reasonably required by them under or for the purposes of the enactments therein specified.' This provision does not apply when the patient is being attended by another doctor for the condition to which the certificate relates; or if the patient is not being treated by a doctor at all for that condition.

"The most difficult questions about the interpretation of this requirement to issue free certificates has arisen in the field of claims made under the Social Security Acts 1975 and 1980.

"The general practitioner is entitled first to ask himself whether the person asking for the medical certificate is being 'attended by another doctor' (other than a partner/assistant or deputy of himself) for the condition to which the certificate relates; or alternatively whether the patient is not being treated for the condition by a doctor at all. If another doctor or no doctor is involved in this way then there is no obligation to issue the certificate. While some nice legal points could be made for the distinction between 'attendance for a condition' and 'treatment of a condition' practitioners are advised that when in doubt they should assume that the two words are synonymous having regard to the definition of 'treatment' in the regulations.

"Subject to their not being excused under these two exceptions the following is considered by the solicitors to be a reasonably comprehensive exposition of the medical circumstances where a doctor should issue a medical certificate free of charge when a patient requires this for the purpose of obtaining benefit under the Social Security Acts:

"(1) Pregnancy.

"(2) 'Serious illness.'

"(3) 'Physical or mental disability.'

"(4) In relation to heating claims: (a) chronic ill health due to bronchitis, rheumatism, arthritis, or anaemia; (b) restricted mobility due to some physical reason; (c) physical illness or physical disability to the extent that the patient is confined to the home or unable to leave it alone; $(d)$ a serious physical illness; (e) confinement to bed or inability to walk unaided within the house coupled with the requirement for heating day and night.

"(5) In relation to attendance needs: (a) a need for frequent attention in connection with bodily functions; $(b)$ a need for continual supervision in order to avoid substantial danger to himself or others.

"(6) In relation to baths-persons who on medical grounds need more than one bath a week.

"(7) In relation to diet-persons who need a special diet because of (a) diabetes, peptic ulcer, conditions of the throat causing serious difficulty in swallowing, ulcerative colitis, tuberculosis needing treatment with drugs, or similar illnesses; (b) convalescence from a major illness or operation or suffering from an illness involving a diet costing more than the normal diet; $(c)$ renal failure for which the patient is being treated by dialysis.

"(8) In relation to claims for extra laundry: (a) where the laundry cannot be done at home because all adult members of the household are ill, disabled, or infirm; (b) where the quantity of laundry is substantially greater because of a patient's incontinence.

"(9) In relation to claims for wear and tear on clothing-where a person suffers from a physical or mental condition, which causes clothing or footwear to wear out unusually quickly."

\section{Central accountability—continued from page 1677}

opportunity than your predecessors to plan and develop services in the light of local needs and circumstances."'13

\section{Future for health authority members}

The degree of discretion exercised by individual health authorities and their emphasis or not on local priorities has been a reflection largely of the absence or fuzziness of objectives and criteria of performance. Under the emerging new system health authorities may still be partners in the policy creation process, to the extent that they engage in a dialogue with the DHSS about objectives and performance. But once these have been set health authorities become executors of nationally agreed policy: in effect, part of the hierarchy of line management.

This leaves health authorities caught trying to reconcile two different roles. How can they best combine representing local interests and acting as line managers? In the formulation of plans they need to act in the former capacity; in the execution of plans they need to act in the latter capacity. This tension always has been present in the NHS, but it is being accentuated by the developing system of output targets. And the ultimate logic of this system would be for health authorities to become smaller, more managerial bodies whose action plans combined local and national policy aims, while the role of local advocacy would be left to community health councils. The councils were created originally for precisely this purpose $^{14}$ and their responsibilities have recently been extended to cover the work of family practitioner committees. ${ }^{15}$

Our analysis would suggest that the way in which the objectives and performance of the NHS are conceptualised moulds, in turn, the organisational structure of the service and the relationship between central government and health authorities. In the decades when the only concern of governments was with defining objectives and performance in terms of inputs much discretion was left to individual health authorities in theory and to professional health providers in practice. We are moving into a second stage, where the concern of central government with outputs-as part of its larger preoccupation with increasing productivity and value for moneyis leading it inexorably to setting local managerial tasks and limiting local professional discretion. And the question now is whether it is possible to move towards a third stage, in which the objectives and performance of the NHS are defined in terms of outcomes, so leaving individual health authorities free to decide on the best means in the light of local circumstances while ensuring that the government can hold them to account for achieving agreed, explicit, and measurable aims. Certainly, unless it proves possible to move towards outcomes, it is difficult to see how the present, rightful emphasis on strengthening accountability can be achieved without also imposing an undesirable degree of rigidity on the NHS.

\section{References}

1 Timmins $N$. Health authorities must cut 2000 posts and plan $£ 150$ million saving. The Times 1985

April 26:2.
2 Day $P$, Klein R. The mobilisation of consent versus the management of conflict: decoding the Griffiths report. Br Med f 1983;287:1813-6.

3 Department of Health and Social Security. Health service plans for 1985-6: the benefits to patients. London: DHSS, 1985.

4 Allen DE. Annual reviews or no annual reviews: the balance of power between the DHSS and health authorities. BrMed I 1982;285:665-7.

5 Social Services Committee. Third report from the social services committee 1979-80: the government's white papers on public expenditure: the social services. London: HMSO, 1980. (HC 702.)

6 Committee of Public Accounts. Seventeenth report from the committee of public accounts 1981-2. Financial control and accounsability in the National Health Service. London: HMSO, 1981. (HC 255.)

7 Prime Minister and Minister for the Civil Service. Efficiency and effectiveness in the civil service. London: HMSO, 1982. (Cmnd 8616.)

8 Prime Minister and Chancellor of the Exchequer. Financial management in government departments. London: HMSO, 1983. (Cmnd 9058.)

9 Department of Health and Social Security. Priorities for health and personal sacial services in England. London: HMSO, 1976.

10 Department of Health and Social Security. Priorities for health and social security: the way forward. London: HMSO, 1977.

11 Scrivens $\mathrm{E}$, et al. A review of the theoretical considerations of outcome indicators. In: Effective Health Care (in press).

12 Klein R. The politics of the National Health Service. London: Longmans, 1983.

13 Department of Health and Social Security. Care in action. London: HMSO, 1981.

14 Klein R, Lewis J. The politics of consumer representation. London: Centre for Studies in Social Policy, 1976.

15 National Health Service. The community health councils regulations, 1985. SI 1985 No 304 . London HMSO, 1985. 